\title{
Institutos Nacionais de Ciência e Tecnologia da área de \\ Ciências Agrárias: estudo da publicação científica, técnica e tecnológica (2013-2015)
}

\author{
Heloisa Costa \\ Márcio Matias \\ Rosangela Schwarz Rodrigues \\ Universidade Federal de Santa Catarina - UFSC, Brasil
}

O R I G I N A L

\begin{abstract}
Resumo
Objetivo. Este artigo aborda a difusão das publicações científicas, técnicas e tecnológicas dos Institutos Nacionais de Ciência e Tecnologia (INCT) da área de Ciências Agrárias, apresentando onde são publicados os resultados de pesquisa e como acontece o acesso da sociedade a esses resultados. O objetivo geral é analisar as publicações e os objetivos específicos são: a) Levantar as características dos pesquisadores vinculados aos INCT; b) Classificar, por tipo, as publicações científicas, técnicas e tecnológicas dos INCT, de 2013 a 2015; c) Identificar o tipo de acesso das publicações científicas, técnicas e tecnológicas.

Método. Os aspectos metodológicos envolveram a utilização de pesquisa exploratória e descritiva, bibliográfica e documental com abordagem quantitativa.

Resultados. O resultado mostra que os INCT da área de Agrárias tiveram uma produção científica, técnica e tecnológica expressiva, apresentando o total de 13.321 publicações, nos anos de 2013 a 2015. Os Institutos divulgaram suas pesquisas por meio de canais formais e informais, sendo que a publicação científica apresentou o total de 10.972 itens, a técnica 2.196 e a publicação tecnológica apresentou o total de 153 itens. As produções científicas, técnicas e tecnológicas, publicadas por meio de canais formais representaram $83 \%$ de todos os itens e os canais informais, 17\%. A publicação de artigos em periódicos representou 52\% da produção científica, que foi publicada em 1008 revistas, pertencentes a 378 editoras diferentes. Em relação ao acesso, as publicações científicas, técnicas e tecnológicas mostram que: 56\% dos itens cadastrados no currículo Lattes dos pesquisadores não foram localizados; $35 \%$ estavam disponíveis na web, em acesso aberto, e $9 \%$ são obtidos por meio de pagamento de busca dos usuários ao realizar as suas buscas no catálogo da biblioteca.
\end{abstract}

Palavras-chave

Ciências Agrárias; Difusão científica; Institutos Nacionais de Ciência e Tecnologia; Transferência e acesso à informação

National Institutes of Science and Technology in the area of Agrarian Sciences: a study of scientific, technical and technological publications (2013-2015)

\begin{abstract}
Objective. This article discusses the diffusion of scientific, technical and technological publications of the National Institutes of Science and Technology (INCT), in the field of Agrarian Sciences, showing where the research results are published and how society's access to these results happens. The general objective is to analyze the publications, and the specific objectives are: a) to raise the characteristics of the researchers linked to the INCT; b) to classify, by type, the scientific, technical and technological publications of the INCT, from 2013 to 2015; c) to identify the type of access of scientific, technical and technological publications.

Method. The methodological aspects involved the use of exploratory and descriptive, bibliographical and documentary research with quantitative approach.

Results. The results present that the INCTs in the field of Agrarian Sciences had a significant scientific, technical and technological production, presenting a total of 13,321 documents in the period from 2013 to 2015. The Institutes make their research work public through formal and informal channels. The scientific production presented a total of 10,972 items, while technical presented 2,196 and technological production presented the total of 153 analyzed items. The scientific, technical and technological productions made public through formal channels presented the total of $83 \%$ of all the items, while the ones made public through informal channels represent $17 \%$. The publication of articles in periodicals represented $52 \%$ of scientific production, which was published in 1,008 journals, belonging to 378 different publishers. Regarding access to scientific, technical and technological publications, the data present that: $56 \%$ of the items registered in the researchers' Lattes curriculum were not located; $35 \%$ were available on the web, in open access, and $9 \%$ were obtained through payment.
\end{abstract}




\section{Introdução}

O tema deste artigo consiste em conhecer como é realizada a difusão das publicações científicas, técnicas e tecnológicas dos Institutos Nacionais de Ciência e Tecnologia (INCT) pertencentes ao campo de estudo de Ciências Agrárias, conforme denominação atribuída pelo Conselho Nacional de Desenvolvimento Científico e Tecnológico (CNPq), apresentando em quais canais são publicados os relatórios dos trabalhos científicos, técnicos e tecnológicos desses Institutos.

Para tanto, são mapeados todos os Institutos de C\&T da área de Agrárias do Brasil, de acordo com o site do INCT, responsável pelo Programa Institutos Nacionais de Ciência Tecnologia, mantido pelo Conselho Nacional de Desenvolvimento Científico e Tecnológico (CNPq), o qual apresenta dados informativos e estatísticos atuais sobre o programa, que está em atuação desde 2008.

O Governo Federal, por meio do Ministério da Educação e do Ministério de Ciência e Tecnologia, criou os INCT, cujo "objetivo é apoiar atividades de pesquisa de alto impacto científico em áreas estratégicas e/ou na fronteira do conhecimento, que visem à busca de solução de grandes problemas nacionais". (CONSELHO NACIONAL DE DESENVOLVIMENTO CIENTÍFICO E TECNOLÓGICO, 2014, p. 1).

Em 2016, de acordo com o site do Programa, existem 125 Institutos de Ciência e Tecnologia no Brasil, que se encontram divididos por área ou região. Os INCT estão estruturados em oito áreas: Humanas e Sociais, Ecologia e Meio Ambiente, Agrárias, Engenharia e Tecnologia da Informação, Nanotecnologia, Energia, Exatas e Naturais, e, Saúde.

Destaca-se que os INCT têm o papel de difundir a ciência e a tecnologia, tanto que, dentre as missões dos institutos, destaca-se a transferência de conhecimento para a sociedade utilizando outros instrumentos além da publicação científica, por meio da difusão de conhecimento com foco no fortalecimento da educação científica da população em geral. (CONSELHO NACIONAL DE DESENVOLVIMENTO CIENTíFICO E TECNOLÓGICO, 2008). Todos os INCT devem "obrigatoriamente prever ações de difusão e disseminação do conhecimento para a sociedade". (CONSELHO NACIONAL DE DESENVOLVIMENTO CIENTÍFICO E TECNOLÓGICO, 2014, p. 30).

Dessa forma, o objetivo geral deste estudo é analisar as publicações científicas, técnicas e tecnológicas dos pesquisadores dos Institutos Nacionais de Ciência e Tecnologia da área de Agrárias; e tem como objetivos específicos: a) levantar as características dos pesquisadores vinculados aos INCT da área de Agrárias; b) classificar as publicações científicas, técnicas e tecnológicas dos INCT da área de agrárias de 2013 a 2015; c) identificar o tipo de acesso das publicações científicas, técnicas e tecnológicas.

\section{Comunicação e publicação científica}

Merton (2013, p. 183) entende que ciência é uma palavra que se refere a itens distintos, mas inter-relacionados, que é utilizada para expressar a combinação de um: "conjunto de métodos característicos por meio dos quais o conhecimento é certificado; estoque de conhecimento acumulado originado da aplicação desses métodos; conjunto de valores e costumes culturais que governam as atividades denominadas científicas".

"A formalização da comunicação científica resulta da necessidade de compartilhamento dos resultados das pesquisas entre o crescente número de cientistas, porquanto a ciência passa de uma atividade privada para uma atividade marcadamente social" (TARGINO, 2000, p. 18).

Na concepção de Mueller (2000, p. 23), "o sistema de comunicação científica [...] inclui todas as formas de comunicação utilizadas pelos cientistas que pesquisam e contribuem para o conhecimento numa determinada área [...]". Essas formas de comunicação se modificam tanto nos canais formais quanto nos informais, à medida que ocorrem os avanços tecnológicos.

Le Coadic (1996) caracteriza os canais formais como sendo os que possuem audiência pública, Informação armazenada de forma permanente e recuperável, comprovada e relativamente antiga, que possui disseminação 
uniforme, redundância moderada e ausência de interação direta. Os canais informais possuem audiência restrita e privada, informação não armazenada, não recuperável, porém recente e geralmente não comprovada, possui a direção do fluxo escolhida pelo produtor, redundância, e, às vezes, muito importante e possui interação direta.

Para Targino (2001), a forma como o sistema de investigação da ciência funciona é de caráter dinâmico, contínuo e cumulativo, e, para que a ciência continue estimulando e orientando a evolução humana, são necessárias "condições mínimas de trabalho, que incluem facilidade de acesso à informação, infraestrutura adequada, possibilidade de comunicação com os pares [...] e oportunidade para divulgação ampla de seus trabalhos".

Assim, "a publicação científica tornou-se, [...] um instrumento indispensável não apenas como meio de promoção individual, mas enquanto forma de promoção e fortalecimento do ciclo de criação, organização e difusão do conhecimento". (BUFREM, 2007, p. 39).

A revisão por pares é a garantia da qualidade da publicação científica. O artigo científico, mesmo na era digital, mantém sua "influência duradoura" e o "[...] artigo revisado por pares como produto final da pesquisa científica pode responder à necessidade de comunicar a informação científica complexa, [...]" (DELFANTI; PITRELLI, 2015, p. 63).

A base da publicação científica são os documentos com os relatos das pesquisas realizadas. Silva e Hayashi (2008) ressaltam que a produção do conhecimento científico no Brasil é realizada por docentes e discentes de graduação e pós-graduação de universidades e instituições que se preocupam em cumprir o rigor científico.

Se a ciência precisa ser comunicada e considerando a necessidade mapear a produção científica e conhecer como os pesquisadores se comunicam e publicam os resultados de pesquisa da área, instituições governamentais de fomento e de investimento no desenvolvimento da ciência, tecnologia e inovação realizam acompanhamentos periódicos sobre o desenvolvimento da ciência no mundo.

Há mais de 20 anos a UNESCO realiza o mapeamento de Ciência, Tecnologia e Inovação (CTI) e emite em Relatório de Ciência a cada cinco anos. O Relatório de 2015 informa um total de 7,8 milhões de cientistas e engenheiros no mundo, número que aumentou em $21 \%$ desde 2007 e reflete também no número de publicações científicas. O total de publicações científicas passou de 28.244, em 2008, para 37.228, em 2014, com um aumento de $31,8 \%$, representando $2,9 \%$ da produção mundial de publicações em 2014. (UNESCO, 2015, p. 18).

A publicação técnica, assim como a científica, é uma forma de comunicar os resultados de pesquisa dos INCT da área de Agrárias. Para Diniz e Oliveira (2015, p. 124), "os registros da produção técnica são feitos em relatórios institucionais, na base de currículos da plataforma Lattes do CNPq e no sistema de avaliação da pósgraduação brasileira, realizado pela CAPES".

A publicação técnica, em sua maioria, é comunicada por meios de canais informais, que se destacam pela rapidez de circulação das informações e a atualidade da informação que é veiculada nesses canais. Em relação ao uso, não há uma separação visível entre as dimensões dos canais formal e informal da comunicação, sendo ambos utilizados pelos pesquisadores para divulgar seus resultados de pesquisa. (STUMPF, 2000).

De acordo com Battaglia (1999) existe uma diferença entre o ciclo da informação científica e o ciclo da informação tecnológica: a informação científica, "[...] é a expressão de todo o conhecimento que envolve a pesquisa básica, aplicada e o desenvolvimento experimental, objetivando o reconhecimento pela comunidade que os criou, a divulgação do novo conhecimento obtido e a propriedade intelectual do pesquisador". Por outro lado, na informação tecnológica "o segredo é fundamental para o seu desenvolvimento e para protegê-la existem as patentes, cujo sistema é estruturado com informações tecnológicas favorecendo o país proprietário da tecnologia", ou seja, envolve sigilo e restrições, normalmente detalhadas em cláusulas contratuais. (BATTAGLIA, 1999, p. 201).

Para o Instituto Nacional da Propriedade Industrial (INPI), informação tecnológica é a informação obtida nos documentos de patentes, que consiste em uma das mais completas fontes de pesquisa. A busca de informação em documentos de patentes é fundamental para orientar as atividades de pesquisa, de acordo com o que já foi ou não pesquisado. (INSTITUTO NACIONAL DA PROPRIEDADE INDUSTRIAL, 2016). 
Para Gonçalves (2014), uma "patente é requerida e concedida para tecnologia, seja de produto inédito ou para aprimorar alguma invenção. O número de patentes é um dos fatores que refletem o grau de inovação de um país [...]".

Os resultados das pesquisas são publicados em diversos tipos de documentos e suportes, cada um com propósitos distintos e complementares. Existem fontes e recursos informacionais disponíveis de forma oral, impressa, digital e multimídia, que possuem funções e conteúdos diferentes, que consequentemente se direcionam a usuários específicos. As fontes de informação são geralmente utilizadas por pesquisadores, acadêmicos (docentes e discentes), e, usuários comuns. Para Pinheiro (2006), as fontes de informação correspondem à origem da informação, existe uma classificação para as diversas origens cujos critérios são o seu conteúdo, propósito ou função.

\subsection{Difusão, divulgação e disseminação científica}

A divulgação científica compreende a "[...] utilização de recursos, técnicas, processos, produtos [...] para a veiculação de informações científicas, tecnológicas ou associadas a inovações ao público leigo". (BUENO, 2009, p. 162).

Para Varella et al. (2012, p. 4) "[...] Todo e qualquer meio de transmissão científica mais popular ou linguagem de melhor acesso para transmissão da ciência são considerados divulgação científica [...], uma extensão para não especialistas".

De acordo com Sanches Mora (2003, p. 13), "divulgação é uma recriação do conhecimento científico, para tornálo acessível ao público", ou seja, a divulgação científica vem com o objetivo de traduzir para o público leigo o que é produzido cientificamente.

O conceito mais amplo relacionado à divulgação é o de difusão científica, que de acordo com Bueno (1984), refere-se a todo e qualquer processo usado para a comunicação da informação científica e tecnológica, podendo ser orientada tanto para o público leigo em geral (o mesmo significado de divulgação), quanto para especialistas (sinônimo de disseminação científica).

"A difusão científica é o ato de anunciar, propagar, publicar, popularizar, comunicar, divulgar, noticiar [...] que podem esclarecer o sentido de difundir o conhecimento para comunidades técnico-científicas, população em geral e de interesse". (VARELLA et al., 2012, p. 4).

A disseminação da informação é conceito sólido na área de Ciência da Informação $(\mathrm{Cl})$, e se refere aos serviços e produtos de informação comuns à área, tais como: bibliografias, resumos, serviços de alerta em geral, biblioteca virtuais e digitais, repositórios, entre outros produtos, próprios da área de $\mathrm{Cl}$ e elaborados para atender ao perfil de um determinado público. (PINHEIRO; VALÉRIO; SILVA, 2009).

Na visão de Varella et al. (2012), a disseminação científica pode ser entendida como um processo, uma estratégia da veiculação de informações científicas e tecnológicas entre um público de especialistas, ou seja, o discurso científico transmitido de forma complexa.

Em suma, a difusão pode ser considerada como o termo mais amplo, que engloba tanto a divulgação como a disseminação. A divulgação é relacionada ao processo de comunicação envolvendo os meios e canais utilizados para comunicar a ciência para um público leigo, e a disseminação refere-se à comunicação da ciência voltada para um público especializado.

\subsection{Acesso à informação científica}

O Brasil tem construído o seu sistema de pesquisa científica baseado em universidades públicas e programas governamentais de pesquisa, apoio do governo para o acesso aberto. A criação de uma plataforma tecnológica de apoio aos periódicos científicos tem permitido ao país atingir um nível considerável de visibilidade internacional em um curto espaço de tempo (RODRIGUES; ABADAL, 2014). 
O acesso aberto se define como a disponibilidade do acesso público à Internet, permitindo que qualquer usuário possa baixar, ler, copiar, distribuir, imprimir, pesquisar os textos completos dos artigos sem contrapartida financeira, jurídica ou barreiras técnicas, sendo assegurados os direitos do autor sobre a integridade do seu trabalho e de ser citado (ALPERIN, 2014).

Com a disponibilização dos artigos em acesso aberto, o andamento das investigações se tornou mais rápido, pois os cientistas podem ter acesso imediato a resultados de pesquisas de seus colegas, agilizando o acesso aos documentos (ABADAL, 2012).

De acordo com o Relatório de Ciência da UNESCO, de 2015, "a Internet trouxe com ela a ciência aberta, abrindo o caminho para a colaboração internacional online em pesquisa, bem como o livre acesso a publicações e dados subjacentes". Isso gera um movimento global em direção da educação aberta, o que faz com que o sistema de pesquisa acadêmica e o ensino superior se internacionalizem rapidamente (PEDROSA; CHAIMOVICH, 2015, p. 35).

Para Albagli (2015, p. 9), ciência aberta é "[...] um processo, algo em construção, que mobiliza interesses e pontos de vista distintos [...] que também permite múltiplas [...] interpretações" e, as "iniciativas mais expressivas nos estágios iniciais do movimento pela ciência aberta dirigiram-se centralmente para o acesso livre a publicações científicas". (ALBAGLI, 2015, p. 11).

No entendimento de Chan, Okune e Sambuli (2015, p. 98), a ciência aberta não se refere apenas à acessibilidade de artigos científicos, mas se estende a outros objetos de pesquisa, tais como: "dados, códigos de software, protocolos e fluxos de trabalho", de maneira que possam ser usados, reutilizados e distribuídos sem restrições legais, sociais ou tecnológicas.

As redes sociais científicas são um novo ponto de encontro para investigadores e um importante instrumento e sua utilização vêm aumentando na comunidade científica, pois são ferramentas práticas para divulgar os resultados da investigação e para compartilhar conhecimento. (GONZALEZ-DIAZ; IGLESIAS-GARCIA; CODINA, 2015).

Acesso aberto, dados abertos, governos abertos, inovação aberta, desenvolvimento aberto, ciência aberta, representam vantagens para toda a sociedade, pois com eles haveria a ampliação da difusão da ciência. $O$ segredo para este caminho é o conhecimento de seus princípios e aplicações (MACHADO, 2015; CHAN; OKUNE; SAMBULI, 2015).

O acesso aberto aparece como um caminho para a divulgação da ciência, pois resulta de esforços da comunidade científica para tornar a informação científica disponível, amplamente acessível e visível a pesquisadores de todo mundo, que estão focados na geração de novos conhecimentos que serão convertidos em benefícios para toda sociedade (LEITE, 2012).

O movimento de acesso aberto possibilitou mudanças em relação à forma como a publicação científica é disponibilizada às pessoas. As coleções de documentos disponíveis em acesso aberto se traduzem na possibilidade de acesso e leitura de pesquisas, o que viabiliza que maior número de pesquisadores e profissionais tenha acesso aos documentos que representam o acervo do desenvolvimento científico de determinada área.

\section{Procedimentos metodológicos}

Para coletar as informações referentes à pesquisa realizou-se a busca no site do Programa INCT (http://inct.cnpq.br/), que possui dados atualizados sobre os institutos. O recorte temporal contabilizou e classificou as publicações nos anos de 2013, 2014 e 2015. A coleta de dados final foi realizada nos meses de abril e maio de 2016, totalizando 444 pesquisadores, que representa o universo total de pesquisadores de todos os 12 institutos da área de Agrárias.

O estudo foi organizado em planilhas de Excel que possibilitaram verificar padrões e elaborar tabelas e gráficos para a apresentação dos resultados. Foram definidas categorias utilizadas na coleta de dados: nome do 
instituto, nome do pesquisador, vínculo institucional de cada pesquisador, se pesquisador CNPq, tipo de publicação científica, técnica e tecnológica, número de publicações no período e ano.

Foi considerada para esta pesquisa a classificação dos tipos de publicação adotada pelo CNPq, por meio do currículo Lattes, com adaptações. Para este estudo foram consideradas as produções bibliográficas (denominadas no estudo de publicação científica) e técnicas, com acréscimo da divisão produções tecnológicas (na qual foram incluídas as patentes e registros, produtos tecnológicos e programas de computador). A classificação seguiu a estrutura apresentada no Quadro 2.

Quadro 2 - Classificação das publicações científicas, técnicas e tecnológicas

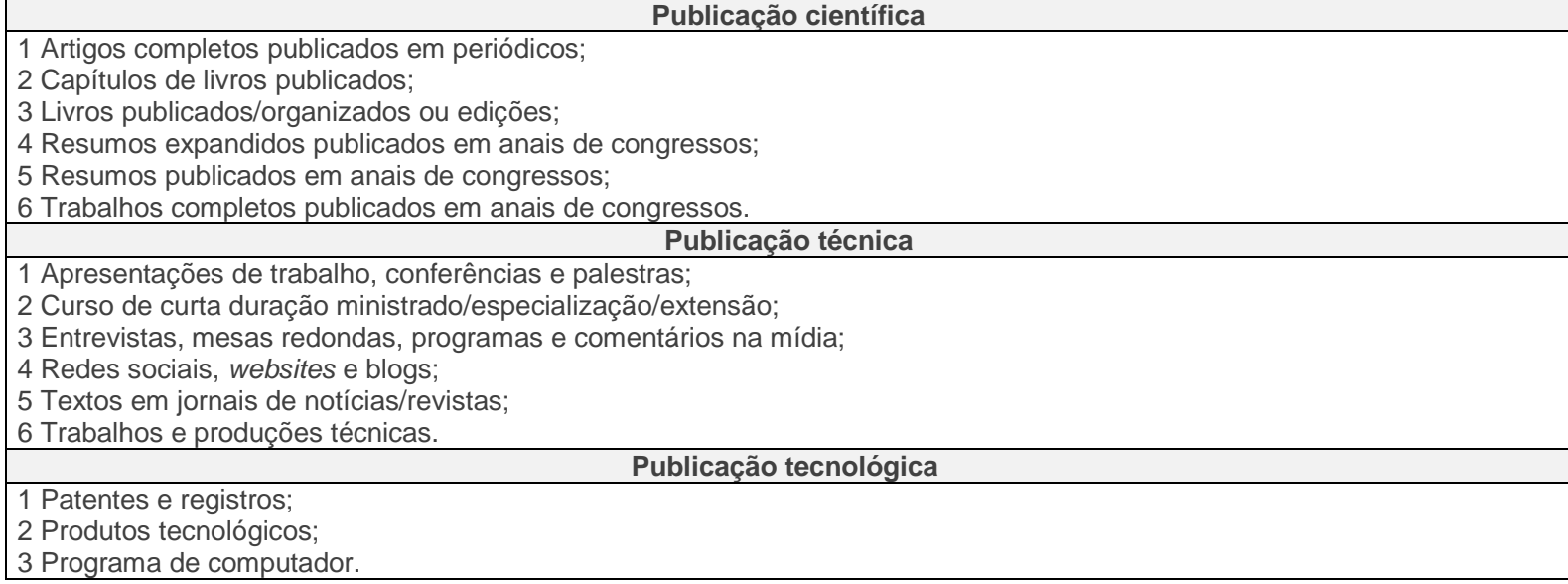

Fonte: Adaptado do currículo Lattes para a pesquisa (2016).

A investigação apresentou algumas limitações, como: à interpretação pessoal dos pesquisadores na hora do cadastramento das informações no sistema Lattes; a eventual desatualização do currículo Lattes; a repetição (duplicação) de artigos cadastrados em campos distintos no sistema ou de artigos no mesmo campo; cadastramento de informações em lugar indevido; data das publicações fora da ordem cronológica; erros de digitação que dificultam na recuperação da informação.

Para a pesquisa foram considerados apenas os pesquisadores que possuem doutorado completo. Não foi possível detalhar o grau de participação de cada doutor no projeto, sendo assim, todos os registrados foram considerados. Os pesquisadores que não possuíam publicações na data de recorte (2013-2015) ou quando os currículos Lattes não foram encontrados, como no caso de pesquisadores estrangeiros, foram descartados.

\section{Resultados e discussão}

\subsection{Pesquisadores vinculados aos INCT da área de agrárias}

Os INCT de Agrárias estão contemplados nas regiões: Sul, Sudeste e Nordeste, sendo que quatro institutos estão situados no estado de Minas Gerais (MG), com 168 pesquisadores, quatro em São Paulo (SP), com 90 pesquisadores, um instituto no Paraná (PR), com 85 pesquisadores, um na Paraíba (PB), com 30 pesquisadores, um no Rio de Janeiro (RJ), com 53 pesquisadores, e, um em Sergipe (SE), com 18 pesquisadores, apresentando um total de 444 pesquisadores, como se pode observar na Tabela 1, que também apresenta o vínculo do pesquisador com o CNPq, na condição de bolsista de produtividade em pesquisa e em Desenvolvimento Técnico e Extensão Inovadora. 
Tabela 1 - Institutos da área de Agrárias e seus pesquisadores

\begin{tabular}{|c|c|c|c|}
\hline INCT & Cidade/Estado & $\begin{array}{c}\text { № de } \\
\text { Pesquisadores }\end{array}$ & $\begin{array}{c}\text { № de } \\
\text { pesquisadores } \\
\text { CNPq }\end{array}$ \\
\hline Fixação Biológica de Nitrogênio & Curitiba (PR) & 85 & 23 \\
\hline Ciência Animal & Viçosa (MG) & 63 & 36 \\
\hline Entomologia Molecular & Rio de Janeiro (RJ) & 53 & 29 \\
\hline $\begin{array}{l}\text { Informação Genético-Sanitária da Pecuária } \\
\text { Brasileira }\end{array}$ & Belo Horizonte (MG) & 45 & 16 \\
\hline Genômica para o Melhoramento de Citros & Cordeirópolis (SP) & 43 & 17 \\
\hline Café & Lavras (MG) & 37 & 24 \\
\hline Controle das Intoxicações por Plantas & Patos (PB) & 30 & 12 \\
\hline Controle Biorracional de Insetos Pragas & São Carlos (SP) & 24 & 10 \\
\hline Interações Planta Praga & Viçosa (MG) & 23 & 15 \\
\hline Frutos Tropicais & São Cristóvão (SE) & 18 & 7 \\
\hline Engenharia da Irrigação & Piracicaba (SP) & 17 & 7 \\
\hline Semioquímicos na Agricultura & Piracicaba (SP) & 6 & 5 \\
\hline Total Geral & & 444 & 201 \\
\hline
\end{tabular}

Fonte: Dados da pesquisa (2016).

As Universidades Federais e a Embrapa representam 83,3\% dos vínculos institucionais dos pesquisadores. 0 fato de os pesquisadores estarem, em sua maioria, atrelados às universidades se deve ao fato de que quase toda pesquisa no Brasil é realizada pelas Universidades. E, o Programa INCT do CNPq tem em uma de suas bases que a difusão de conhecimento deve ser conduzida por seus pesquisadores e pelos bolsistas a ele vinculados (CONSELHO NACIONAL DE DESENVOLVIMENTO CIENTíFICO E TECNOLÓGICO, 2008). Ou seja, os Institutos são formados por pesquisadores que atuam nas Universidades, onde são professores e alguns atuam como coordenadores dos Institutos.

Quanto à relação entre pesquisadores e bolsistas, dos seis pesquisadores do INCT Semioquímicos na Agricultura, cinco (83,3\%) são bolsistas de produtividade do CNPq, em seguida aparece o INCT Interações Planta Praga, que dos 23 pesquisadores, 15 (65,2\%) são vinculados ao CNPq e, em terceiro lugar aparece o INCT Café, que dos 37, 24 (64,9\%) são pesquisadores do CNPq.

O INCT com maior número de pesquisadores atuando como bolsista de produtividade CNPq é o Ciência Animal, com 36 pesquisadores, seguido do INCT Entomologia Molecular, com 25, e o INCT Café, com 24 pesquisadores cadastrados. Todos os INCT possuem pesquisadores atuando como bolsistas de produtividade dentro de uma das 19 subáreas do conhecimento dentro das ciências agrárias.

No total de pesquisadores analisados, 201 são pesquisadores de produtividade do CNPq, representando 45,3\% do total. A maioria dos pesquisadores se concentra em cinco áreas principais: Agronomia, Zootecnia, Medicina Veterinária, Microbiologia e Parasitologia e, Biofísica e Bioquímica.

\subsection{Análise da publicação científica}

Para a publicação científica foram elencadas seis categorias, cujo total de itens contabilizados foi de 10.972. A Tabela 2 apresenta o número de publicação científica por INCT e o total geral nas categorias selecionadas, seguindo a classificação do currículo Lattes. 
Tabela 2 - Publicação científica dos INCT de Agrárias por tipo (2013 a 2015)

\begin{tabular}{|c|c|c|c|c|c|c|c|c|}
\hline Institutos & Art. Per. & Res. anais & $\begin{array}{l}\text { Res. Exp. } \\
\text { anais }\end{array}$ & $\begin{array}{l}\text { Trab. } \\
\text { completo } \\
s \text { anais }\end{array}$ & $\begin{array}{l}\text { Cap. } \\
\text { livros }\end{array}$ & Livros & $\begin{array}{l}\text { Total/ } \\
\text { INCT }\end{array}$ & $\underset{\%}{\text { Total/INCT }}$ \\
\hline Ciência Animal & $\begin{array}{c}1.189 \\
(20,8 \%)\end{array}$ & $\begin{array}{c}649 \\
(23,6 \%)\end{array}$ & $\begin{array}{c}625 \\
(41,9 \%)\end{array}$ & $\begin{array}{c}177 \\
(36,8 \%)\end{array}$ & $91(20,0 \%)$ & $\begin{array}{c}35 \\
(39,8 \%)\end{array}$ & 2.766 & $25,2 \%$ \\
\hline $\begin{array}{l}\text { Fixação Biológica de } \\
\text { Nitrogênio }\end{array}$ & $\begin{array}{c}747 \\
(13,1 \%)\end{array}$ & $\begin{array}{c}397 \\
(14,5 \%)\end{array}$ & $\begin{array}{c}125 \\
(8,4 \%)\end{array}$ & $31(6,4 \%)$ & $53(11,6 \%)$ & $8(9,1 \%)$ & 1.361 & $12,4 \%$ \\
\hline $\begin{array}{l}\text { Informação Genético- } \\
\text { Sanitária da Pecuária } \\
\text { Brasileira }\end{array}$ & $\begin{array}{c}649 \\
(11,4 \%)\end{array}$ & $\begin{array}{c}358 \\
(13,0 \%)\end{array}$ & $\begin{array}{c}152 \\
(10,2 \%)\end{array}$ & $\begin{array}{c}78 \\
(16,2 \%)\end{array}$ & $54(11,9 \%)$ & $4(4,5 \%)$ & 1.295 & $11,8 \%$ \\
\hline Café & $\begin{array}{c}587 \\
(10,3 \%)\end{array}$ & $273(9,9 \%)$ & $\begin{array}{c}251 \\
(16,8 \%)\end{array}$ & $37(7,7 \%)$ & $90(19,8 \%)$ & $9(10,2 \%)$ & 1.247 & $11,4 \%$ \\
\hline Citros & $431(7,5 \%)$ & $\begin{array}{c}331 \\
(12,0 \%)\end{array}$ & $\begin{array}{c}143 \\
(9,6 \%)\end{array}$ & $3(0,6 \%)$ & $45(9,9 \%)$ & $7(8,0 \%)$ & 960 & $8,7 \%$ \\
\hline $\begin{array}{l}\text { Controle de Intoxicação } \\
\text { Plantas }\end{array}$ & $563(9,9 \%)$ & $90(3,3 \%)$ & $88(5,9 \%)$ & $13(2,7 \%)$ & $7(1,5 \%)$ & $3(3,4 \%)$ & 764 & $7,0 \%$ \\
\hline Entomologia Molecular & $486(8,5 \%)$ & $161(5,9 \%)$ & $4(0,3 \%)$ & $1(0,2 \%)$ & $27(5,9 \%)$ & $2(2,3 \%)$ & 681 & $6,2 \%$ \\
\hline Interação Planta Praga & $300(5,3 \%)$ & $148(5,4 \%)$ & $6(0,4 \%)$ & $2(0,4 \%)$ & $25(5,5 \%)$ & $3(3,4 \%)$ & 484 & $4,4 \%$ \\
\hline $\begin{array}{l}\text { Controle Birracional de } \\
\text { Insetos Praga }\end{array}$ & $290(5,1 \%)$ & $118(4,3 \%)$ & $3(0,2 \%)$ & $8(1,7 \%)$ & $9(2,0 \%)$ & $2(2,3 \%)$ & 430 & $3,9 \%$ \\
\hline Frutos Tropicais & $190(3,3 \%)$ & $122(4,4 \%)$ & $17(1,1 \%)$ & $\begin{array}{c}58 \\
(12,1 \%)\end{array}$ & $21(4,6 \%)$ & $1(1,1 \%)$ & 409 & $3,7 \%$ \\
\hline $\begin{array}{l}\text { Engenharia } \\
\text { Irrigação }\end{array}$ & $183(3,2 \%)$ & $31(1,1 \%)$ & $72(4,8 \%)$ & $\begin{array}{c}73 \\
(15,2 \%)\end{array}$ & $26(5,7 \%)$ & $\begin{array}{c}13 \\
(14,8 \%)\end{array}$ & 398 & $3,6 \%$ \\
\hline $\begin{array}{l}\text { Semioquímicos } \\
\text { Agricultura }\end{array}$ & $95(1,7 \%)$ & $69(2,5 \%)$ & $5(0,3 \%)$ & - $(0,0 \%)$ & $7(1,5 \%)$ & $1(1,1 \%)$ & 177 & $1,6 \%$ \\
\hline Total/Tipo & 5.710 & 2.747 & 1.491 & 481 & 455 & 88 & 10.972 & $100 \%$ \\
\hline Total/Tipo \% & $52,0 \%$ & $25,0 \%$ & $13,6 \%$ & $4,4 \%$ & $4,1 \%$ & $0,8 \%$ & $100 \%$ & \\
\hline
\end{tabular}

Fonte: Dados da pesquisa (2015).

Ressalta-se que a maioria da publicação é composta por artigos, representando $52,0 \%$, os resumos publicados em anais de congresso são $25,0 \%$, seguidos dos resumos expandidos com $13,6 \%$.

Do total de artigos publicados, vale destacar que 1.189 (20,8\%) são pertencentes ao INCT Ciência Animal, em segundo lugar aparece o INCT Fixação Biológica de Nitrogênio, com 747 (13,1\%) publicações; e em terceiro o INCT Pecuária, com 649 (11,4\%) publicações de artigos.

Os Resumos e os Resumos expandidos publicados em anais de congressos alcançam 38,6\% das publicações dos INCT com 4.238 unidades. Em relação aos resumos, o INCT Ciência Animal apresenta 649 (23,6\%) itens, do INCT Fixação Biológica de Nitrogênio com 397 (14,5\%) e o INCT Pecuária 358 (13,0\%). Em relação aos resumos expandidos, o destaque fica para o INCT Ciência Animal com 625 (41,9\%), INCT Café com 251 (16,8\%) e INCT Pecuária com $152(10,2 \%)$.

Em relação aos Trabalhos completos publicados em anais de congressos destaca-se que o INCT Ciência Animal obteve o maior número de ocorrências, com 177 (36,8\%) trabalhos registrados no currículo Lattes dos pesquisadores e o INCT Pecuária, com 78 (16,2\%) trabalhos e o INCT Engenharia de Irrigação, com 73 (15,2\%) trabalhos publicados em anais de congressos.

Em relação aos Capítulos de Livros, o destaque no número de publicações ficou para o INCT Ciência Animal com $91(20,0 \%)$ e para o INCT Café com $90(19,8 \%)$.

Na publicação de Livros, novamente o INCT Ciência Animal apresentou o maior número, com 35 livros (39,8\%), seguido do INCT Engenharia de Irrigação com 13 (14,8\%) publicações, do total de 88 livros publicados, organizados ou edições. 
Em relação ao resultado global da publicação científica dos INCT da área de Agrárias, pode-se compreender que os Institutos que demonstraram maior destaque no número de publicações foram: INCT Ciência Animal apresentando $2.766(25,2 \%)$ de toda publicação científica, INCT Fixação Biológica de Nitrogênio com 1.361 (12,4\%), INCT Pecuária com 1.295 (11,80\%) e INCT Café com 1.247 (11,4\%), que representam juntos 60,8\% de toda publicação científica.

\subsection{Análise da publicação técnica}

Para a publicação técnica foram definidas seis categorias, apresentando o total de 2.196 itens contabilizados, conforme aponta a Tabela 3.

Tabela 3 - Publicação técnica dos INCT de Agrárias por tipo (2013 a 2015)

\begin{tabular}{|c|c|c|c|c|c|c|c|c|}
\hline INCT & $\begin{array}{l}\text { Apres., } \\
\text { conf. } \\
\text { palestras }\end{array}$ & $\begin{array}{l}\text { Trab. } \\
\text { produções } \\
\text { técnicas }\end{array}$ & $\begin{array}{l}\text { Entrev., } \\
\text { mesas } \\
\text { redondas }\end{array}$ & $\begin{array}{l}\text { Textos } \\
\text { jornais } \\
\text { notícias } \\
\text { revistas }\end{array}$ & $\begin{array}{l}\text { Curso } \\
\text { curta } \\
\text { duração } \\
\text { ministr. }\end{array}$ & $\begin{array}{l}\text { Redes } \\
\text { sociais, } \\
\text { sites } \\
\text { blogs }\end{array}$ & $\begin{array}{l}\text { Total } \\
\text { Geral }\end{array}$ & $\begin{array}{c}\text { Total } \\
\text { Geral } \\
\%\end{array}$ \\
\hline Ciência Animal & $173(18,2 \%)$ & $36(8,1 \%)$ & $141(37,8 \%)$ & $42(18,7 \%)$ & $45(23,3 \%)$ & $-(0,0 \%)$ & 437 & $19,9 \%$ \\
\hline Citros & $114(12,0 \%)$ & $125(28,3 \%)$ & $100(26,8 \%)$ & $57(25,3 \%)$ & $25(13,0 \%)$ & $3(21,4 \%)$ & 424 & $19,3 \%$ \\
\hline $\begin{array}{l}\text { Informação } \\
\text { Genético-Sanitária } \\
\text { da } \quad \text { Pecuária } \\
\text { Brasileira }\end{array}$ & $158(16,6 \%)$ & $43(9,7 \%)$ & $44(11,8 \%)$ & $49(21,8 \%)$ & $21(10,9 \%)$ & $2(14,3 \%)$ & 317 & $14,4 \%$ \\
\hline Café & $113(11,9 \%)$ & $72(16,3 \%)$ & $22(5,9 \%)$ & $30(13,3 \%)$ & $26(13,5 \%)$ & $1(7,1 \%)$ & 264 & $12,0 \%$ \\
\hline $\begin{array}{l}\text { Fixação Biológica de } \\
\text { Nitrogênio }\end{array}$ & $111(11,7 \%)$ & $36(8,1 \%)$ & $21(5,6 \%)$ & $10(4,4 \%)$ & $32(16,6 \%)$ & $4(28,6 \%)$ & 214 & $9,7 \%$ \\
\hline $\begin{array}{l}\text { Entomologia } \\
\text { Molecular }\end{array}$ & $65(6,8 \%)$ & $21(4,8 \%)$ & $31(8,3 \%)$ & $4(1,8 \%)$ & $15(7,8 \%)$ & $1(7,1 \%)$ & 137 & $6,2 \%$ \\
\hline $\begin{array}{l}\text { Controle Intoxicação } \\
\text { Por Plantas }\end{array}$ & $32(3,4 \%)$ & $48(10,9 \%)$ & $1(0,3 \%)$ & $5(2,2 \%)$ & $11(5,7 \%)$ & - $(0,0 \%)$ & 97 & $4,4 \%$ \\
\hline $\begin{array}{ll}\text { Controle } & \text { Birracional } \\
\text { de } & \text { Intoxicação } \\
\text { Plantas } & \end{array}$ & $58(6,1 \%)$ & $20(4,5 \%)$ & $3(0,8 \%)$ & $2(0,9 \%)$ & $9(4,7 \%)$ & - $(0,0 \%)$ & 92 & $4,2 \%$ \\
\hline $\begin{array}{l}\text { Engenharia } \quad \text { de } \\
\text { Irrigação }\end{array}$ & $47(5,0 \%)$ & $10(2,3 \%)$ & $3(0,8 \%)$ & $11(4,9 \%)$ & $4(2,1 \%)$ & - $(0,0 \%)$ & 75 & $3,4 \%$ \\
\hline Frutos Tropicais & $23(2,4 \%)$ & $23(5,2 \%)$ & $4(1,1 \%)$ & $4(1,8 \%)$ & $5(2,6 \%)$ & $3(21,4 \%)$ & 62 & $2,8 \%$ \\
\hline $\begin{array}{l}\text { Interação } \\
\text { Praga }\end{array}$ & $41(4,3 \%)$ & $3(0,7 \%)$ & $3(0,8 \%)$ & $4(1,8 \%)$ & $-(0,0 \%)$ & - $(0,0 \%)$ & 51 & $2,3 \%$ \\
\hline $\begin{array}{l}\text { Semioquímicos na } \\
\text { Agricultura }\end{array}$ & $14(1,5 \%)$ & $5(1,1 \%)$ & - $(0,0 \%)$ & $7(3,1 \%)$ & - $(0,0 \%)$ & - $(0,0 \%)$ & 26 & $1,2 \%$ \\
\hline Total/Tipo & 949 & 442 & 373 & 225 & 193 & 14 & 2.196 & $100 \%$ \\
\hline Total/Tipo \% & $43,2 \%$ & $20,1 \%$ & $17,0 \%$ & $10,2 \%$ & $8,8 \%$ & $0,6 \%$ & $100 \%$ & \\
\hline
\end{tabular}

Fonte: Dados da pesquisa (2016).

Apresentações de trabalho, conferências e palestras apresentam 949 (43,2\%) e Trabalhos e produções técnicas apresentam 442 (20,1\%), com o total de 1391 (63,3\%) dos tipos de publicação técnica, seguidos pelas Entrevistas, mesas redondas, programas e comentários mídia, com 373 (17,0\%).

No item Apresentação de trabalhos, conferências e palestras, o destaque foi para o INCT Ciência Animal, com $173(18,2 \%)$ trabalhos apresentados, o INCT Pecuária com 158 (16,6\%), e o INCT Citros, com 114 (12,0\%) ocorrências.

Em relação aos Trabalhos e produções técnicas destacam-se os números do INCT Citros, com 125 (28,3\%) tipos de trabalhos técnicos e o INCT Café, com 72 (16,3\%). 
As Entrevistas, mesas redondas, programas e comentários na mídia aparecem em terceiro lugar em número de ocorrências, dos seis itens avaliados, apresentando um número expressivo, com 373 itens (17,0\%). O destaque foi para o INCT Ciência Animal, com 141 itens (37,8\%), o INCT Citros, com 100 (26,8\%) e o INCT Pecuária, com 44 ocorrências (11,8\%).

Em relação aos Textos publicados em jornais e revistas, ressalta-se que o INCT Citros aparece com 57 itens (25,3\%), o INCT Pecuária com 49 (21,8\%) e o INCT Ciência Animal, com 42 documentos (18,7\%).

Em relação aos Cursos de curta duração ministrados, especialização ou extensão, o destaque vai para os INCT Ciência Animal, com 45 itens (23,3\%) e INCT Fixação Biológica de Nitrogênio, com 32 itens (16,6\%). Estes cursos são importantes, pois são formas de capacitação permanente para um público especializado, que vai replicar para a sociedade, como por exemplo, para o agricultor, no campo, as informações sobre determinado assunto, em relação às práticas, processos e novas tecnologias.

As Redes sociais, websites e blogs, apesar de representarem apenas $0,6 \%$ do total da publicação técnica, envolvem a divulgação dos projetos em andamento, o que reflete a preocupação dos INCT Fixação Biológica de Nitrogênio, Frutos Tropicais, Citros, Pecuária, Café e Entomologia Molecular, que somam o total de 14 ocorrências de publicações por meio desses canais.

Em relação ao resultado global da publicação técnica dos INCT da área de Agrárias, destaca-se que os Institutos que apresentaram maior número de publicações foram: INCT Ciência Animal, com 437, que representa 19,9\% do total de publicações, seguido do INCT Citros, com 424 itens (19,3\%), INCT Pecuária, com 317 (14,4\%) e INCT Café, com 264 (12,0\%) dentro dos tipos de publicação analisados.

Percebe-se que o maior número de ocorrências se refere aos canais informais, como a apresentação de trabalhos em eventos, como congressos, seminários e palestras, que aparecem com $949(43,2 \%)$ do total dos itens analisados. A categoria Trabalhos e produções técnicas aparece com 442 itens $(20,1 \%)$. Esta categoria se refere a trabalhos técnicos que geram documentos como: Comunicado técnico, Circular técnica, Apostilas e Manuais, Capítulo de livro não indexado, Boletim Técnico, Pesquisas, editorial, Folder, Folheto Informativo para a população em geral, Desenvolvimento de material didático ou instrucional, Desenvolvimento de material didático ou instrucional, Apostila, Disseminação da Ciência no Município e Boletim de pesquisa e desenvolvimento. Entrevistas e textos em jornais e revistas também aparecem com certa relevância na publicação técnica, apresentando o total de 17,0\%.

\subsection{Análise da publicação tecnológica}

Para a publicação tecnológica foram definidas três categorias, com o total de 153 itens contabilizados, conforme demonstra a Tabela 4.

Das três categorias da publicação tecnológica destacam-se as Patentes e produções técnicas, com 110 itens (71,9\%), seguidos dos Produtos tecnológicos, com 29 (19,0\%) e do Programa de computador, com 14 (9,2\%).

O total de Patentes e registros foi de 110 itens. Os Institutos que mais registraram patentes foram o INCT Citros, com 31 (28,2\%) patentes registradas, o Café com 19 (17,3\%), e o Controle Birracional de Intoxicação Plantas, com 17 (15,5\%). Nos Produtos tecnológicos se destaca o INCT Citros, com 16 ocorrências (55,2\%) e o INCT Frutos Tropicais com sete ocorrências (24,1\%). Na categoria Programas de computador se apresentaram menor número de ocorrência. Destaca-se o INCT Engenharia de Irrigação, com cinco ocorrências e o INCT Ciência Animal, com quatro $(28,6 \%)$. 
Tabela 4 - Publicação tecnológica dos INCT de Agrárias por tipo (2013 a 2015)

\begin{tabular}{|c|c|c|c|c|c|}
\hline Institutos & $\begin{array}{l}\text { Patentes e } \\
\text { registros }\end{array}$ & $\begin{array}{l}\text { Produtos } \\
\text { tecnológicos }\end{array}$ & $\begin{array}{l}\text { Programa de } \\
\text { computador }\end{array}$ & $\begin{array}{l}\text { Total } \\
\text { Geral }\end{array}$ & $\begin{array}{l}\text { Total } \\
\text { Geral \% }\end{array}$ \\
\hline Citros & $31(28,2 \%)$ & $16(55,2 \%)$ & $2(14,3 \%)$ & 49 & $32,0 \%$ \\
\hline Café & $19(17,3 \%)$ & $4(13,8 \%)$ & $1(7,1 \%)$ & 24 & $15,7 \%$ \\
\hline Controle Birracional de Intoxicação Plantas & $17(15,5 \%)$ & $1(3,4 \%)$ & $-(0,0 \%)$ & 18 & $11,8 \%$ \\
\hline Entomologia Molecular & $13(11,8 \%)$ & $-(0,0 \%)$ & $1(7,1 \%)$ & 14 & $9,2 \%$ \\
\hline Frutos Tropicais & $4(3,6 \%)$ & $7(24,1 \%)$ & $-(0,0 \%)$ & 11 & $7,2 \%$ \\
\hline Fixação Biológica de Nitrogênio & $9(8,2 \%)$ & $-(0,0 \%)$ & $1(7,1 \%)$ & 10 & $6,5 \%$ \\
\hline Ciência Animal & $4(3,6 \%)$ & $-(0,0 \%)$ & $4(28,6 \%)$ & 8 & $5,2 \%$ \\
\hline Engenharia de Irrigação & $-(0,0 \%)$ & $-(0,0 \%)$ & $5(35,7 \%)$ & 5 & $3,3 \%$ \\
\hline $\begin{array}{l}\text { Informação Genético-Sanitária da Pecuária } \\
\text { Brasileira }\end{array}$ & $4(3,6 \%)$ & $1(3,4 \%)$ & $-(0,0 \%)$ & 5 & $3,3 \%$ \\
\hline Semioquímicos na Agricultura & $4(3,6 \%)$ & $-(0,0 \%)$ & $-(0,0 \%)$ & 4 & $2,6 \%$ \\
\hline Interação Planta Praga & $4(3,6 \%)$ & $-(0,0 \%)$ & $-(0,0 \%)$ & 4 & $2,6 \%$ \\
\hline Controle Intoxicação por Planta & $1(0,9 \%)$ & $-(0,0 \%)$ & - $(0,0 \%)$ & 1 & $0,7 \%$ \\
\hline Total/Tipo & 110 & 29 & 14 & 153 & $100 \%$ \\
\hline Total/Tipo \% & $71,9 \%$ & $19,0 \%$ & $9,2 \%$ & $100 \%$ & \\
\hline
\end{tabular}

Fonte: Dados da pesquisa (2015).

No levantamento total dos itens registrados no currículo Lattes dos pesquisadores destaca-se o total de 13.321 itens contabilizados referentes à publicação científica, técnica e tecnológica.

\subsection{Acesso às publicações científicas}

Em relação aos artigos publicados em periódicos, a unidade de análise nesta etapa da pesquisa passou a ser o periódico. Foram compiladas 1.008 revistas, apresentando-se o tipo de acesso e a qual editora estas revistas estão vinculadas. Para classificar os tipos de acesso foram definidas as categorias de acesso às revistas, conforme apresenta o Gráfico 1.

\section{Gráfico 1 - Tipo e percentual de acesso dos periódicos científicos}

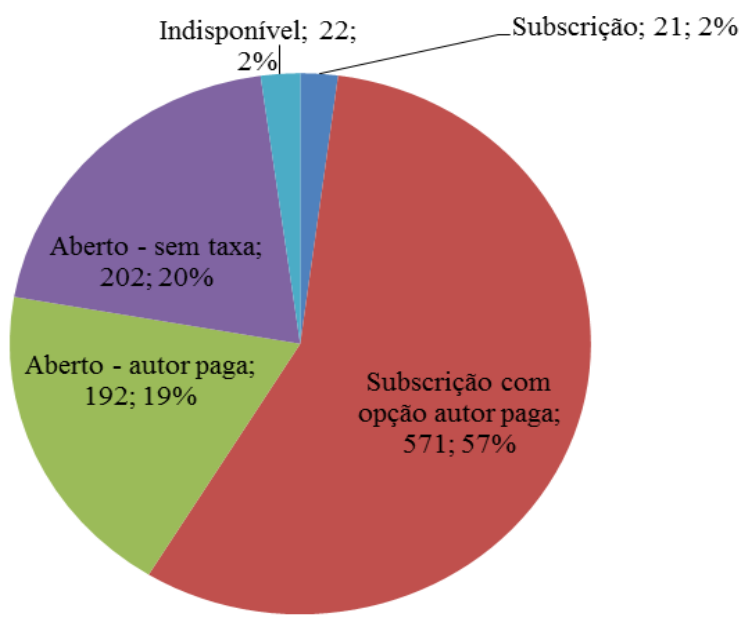


As 1.008 revistas científicas analisadas pertencem a 378 editoras científicas diferentes, sendo que dessas, a Elsevier possui 163 revistas e a Springer, 132 revistas, a Wiley Online Library, 94 revistas e a Taylor \& Francis com 31 revistas, o que representa $41,67 \%$ do total das revistas nas quais foram publicados os artigos.

Esta informação se confirma no estudo de Larivière, Haustein e Mongeon (2015), no qual os resultados mostraram que as maiores editoras (Reed-Elsevier, Wiley-Blackwell, Springer, Wolters Kluwer e Taylor \& Francis) controlam mais da metade do mercado de publicações científicas de revistas das Ciências Naturais e Médicas e nas Ciências Sociais.

Das 1.008 revistas, 606 pertencem a 37 editoras; 305 revistas possuem apenas uma revista cada; 72 revistas são de 36 editoras diferentes, ou seja, cada editora possui duas revistas, o que mostra a dispersão na publicação de artigos científicos. Em relação às taxas de processamento dos artigos, destaca-se que $78 \%$ dos periódicos cobram algum tipo de taxa dos autores para a submissão dos artigos e para o usuário para acessar os artigos publicados pelas editoras.

Das 1.008 revistas analisadas, $11,60 \%$ são mantidas por universidades nacionais e estrangeiras, sendo que $10,42 \%$ das revistas são de universidades brasileiras, das quais $71 \%$ são livres de taxas para autores e/ou leitores, o que representa 75 títulos de revistas.

Larivière, Haustein e Mongeon (2015) comentam que as editoras comerciais se beneficiam mesmo na era digital onde há maior possibilidade de acesso, tendo em vista o aumento da quantidade de literatura científica que publicam, e a consequente necessidade que a comunidade científica tem de ler esta literatura. Mesmo as universidades produzindo e gerenciando o que publicam, por meio de suas editoras, a publicação de periódicos tornou-se comercializada e algumas partes da literatura científica e técnica estão sendo monopolizadas por conglomerados de publicações multinacionais.

Os pesquisadores jovens precisam publicar em revistas de prestígio para ganhar posse, enquanto pesquisadores mais velhos precisam fazer o mesmo para manter seus subsídios e, nesse ambiente, publicar em revistas de alto impacto como Elsevier ou Springer é o que 'conta'. (LARIVIĖRE; HAUSTEIN; MONGEON, 2015).

A Tabela 5 apresenta o resultado geral das categorias da publicação científica (sem considerar os artigos de periódicos, devido à categorização de acesso ter sido feita de forma diferente dos demais itens), que foi a seguinte: dos 1.747 itens de informação pesquisados, 279 itens de informação, que correspondem a $(16,0 \%)$ podem ser obtidos por meio de pagamento, 643 (36,8\%) não foram localizados e 825 (47,2\%) estão disponíveis na web, o que demonstra um resultado maior do que os artigos em relação ao acesso de documentos.

Tabela 5 - Publicação científica dos INCT de Agrárias por tipo de acesso (2013 a 2015)

\begin{tabular}{lccccc}
\hline Categorias & Disponível na web & Não localizado & Compra & Total & Total \% \\
\hline Resumos publicados em anais de congressos & $315(50,8 \%)$ & $282(45,5 \%)$ & $23(3,7 \%)$ & $\mathbf{6 2 0}$ & $\mathbf{3 5 , 5 \%}$ \\
$\begin{array}{l}\text { Resumos expandidos publicados em anais de } \\
\text { congressos }\end{array}$ & $281(61,9 \%)$ & $171(37,7 \%)$ & $2(0,4 \%)$ & $\mathbf{4 5 4}$ & $\mathbf{2 6 , 0} \%$ \\
Capítulos de livros publicados & $66(19,0 \%)$ & $71(20,4 \%)$ & $211(60,6 \%)$ & $\mathbf{3 4 8}$ & $\mathbf{1 9 , 9} \%$ \\
$\begin{array}{l}\text { Trabalhos completos publicados em anais de } \\
\text { congressos }\end{array}$ & $145(58,5 \%)$ & $98(39,5 \%)$ & $5(2,0 \%)$ & $\mathbf{2 4 8}$ & $\mathbf{1 4 , 2 \%}$ \\
$\begin{array}{l}\text { Livros publicados, organizados ou edições } \\
\text { Total }\end{array}$ & $18(23,4 \%)$ & $21(27,3 \%)$ & $38(49,4 \%)$ & $\mathbf{7 7}$ & $\mathbf{4 , 4} \%$ \\
Total \% & $\mathbf{8 2 5}$ & $\mathbf{6 4 3}$ & $\mathbf{2 7 9}$ & $\mathbf{1 . 7 4 7}$ & $\mathbf{1 0 0 \%}$ \\
\hline
\end{tabular}

Fonte: Dados da pesquisa (2016). 
Foram levantados 77 livros, divididos nas categorias: 'Compra', 'Não localizado' e 'Disponível na web', sendo que desse total $38(49,4 \%)$ tem seu acesso por meio de pagamento. Muitos deles estão disponíveis em livrarias, com compra para versão impressa. Os Institutos que mais publicaram livros foram: o INCT Engenharia da Irrigação, com 19 livros (24,7\%) e o INCT Ciência Animal, com 15 livros (19,5\%).

O total de capítulos de livros identificados na web foi de 348, dos quais 211 são acessíveis por meio de pagamento, que representa $60,6 \%$ do total analisado. O INCT que mais publicou capítulos de livros foi o Café (19\%). O Instituto que mais apresentou capítulos de livros acessíveis na web foi o INCT da Fixação Biológica de Nitrogênio, com 20 capítulos disponíveis na web. Os percentuais para as categorias de acesso foram: compra 211 (60,6\%); não localizado, 71 (20,4\%), e, disponível na web, 66 (19\%).

Dos 454 eventos pesquisados, 281 tinham seus resumos expandidos disponíveis na web, representando 61,9\% de documentos disponíveis para consulta e dois documentos possuem seu acesso por meio de pagamento, ambos os eventos organizados por grandes editoras Elsevier e Springer. O INCT Fixação Biológica de Nitrogênio foi o que apresentou maior número de trabalhos publicados em anais disponíveis na web, pois dos $170(51,8 \%)$ eventos pesquisados, 88 estavam acessíveis.

Foram consultados na Internet 620 eventos nos quais os pesquisadores publicaram seus resumos. O INCT Pecuária foi o que apresentou mais resumos publicados em anais de congresso, com 118 itens (19\%), sendo 61 $(51,7 \%)$ disponíveis para acesso, seguidos do INCT Ciência Animal, com 89 (14,4\%) e INCT Citros, com 88 $(14,2 \%)$. Destaca-se que $50,8 \%$ do total tinham anais disponíveis na web, seja em PDF, html ou bases de dados. Os documentos não localizados foram correspondentes a 282 (45,5\%) dos eventos consultados na Internet.

Os Trabalhos completos publicados em anais de congressos contaram 248 incidências, sendo que destas, 145 (58,5\%) tinham anais disponíveis na web e 98 (39,5\%) não foram localizados. O INCT Engenharia da Irrigação apresentou mais documentos disponíveis na web, com 35 das 37 publicações disponíveis para consulta.

As publicações científicas disponíveis em livros e capítulos de livros representam 425 (24,3\%) do total de publicações científicas e 249 (13,3\%) são adquiridos por meio de pagamento e estão formato PDF ou html. Para os documentos oriundos de eventos científicos, como os anais de resumos, resumos expandidos e trabalhos completos, destaca-se o percentual de $75,7 \%$ e $78 \%$ dos periódicos científicos necessitam de pagamento para publicação ou acesso. Isto acontece porque os custos de publicação e manutenção de uma revista científica devem ser mantidos com algum tipo de recurso e, as assinaturas e taxas de publicação são formas de obter esses recursos. Porém, o acesso aos resultados de pesquisa, publicados nos periódicos, não estão disponíveis gratuitamente aos interessados, tornam-se uma barreira.

\subsection{Acesso às publicações técnicas}

$\mathrm{Na}$ recuperação de documentos da publicação técnica percebe-se que é difícil resgatar, devido ao fato de a informação não ser padronizada como na publicação científica. Esta gera documentos formais cadastrados em suportes que exigem tratamento técnico, como periódicos e livros.

Sobre as Apresentações de trabalho, 96\% das conferências e palestras não foram recuperadas na web e $4 \%$ foram recuperadas, resultado que se deve ao fato de as referências estarem cadastradas no currículo Lattes de forma incompleta, não seguindo o padrão recomendado (ABNT ou APA).

Em relação aos Trabalhos e produções técnicas, 53,2\% estavam disponíveis na web e 45,8\% não foram localizados. As informações estruturadas, como: boletins de pesquisa e desenvolvimento, circular técnica, divulgação de informação, folder técnico e material instrucional, foram mais prontamente recuperadas, tendo em vista que são documentos produzidos e disponibilizados pela Embrapa em suas bases de dados, representando $89,6 \%$ dos materiais.

Quando verificados os Cursos de curta duração ministrados, especialização ou extensão, novamente impossibilidade de localização predominou, pois $99 \%$ dos itens não foram recuperados. 
No item Entrevistas, mesas redondas, programas e comentários na mídia, mesmo apresentando informações incompletas foi possível recuperar $49 \%$ destes itens, a maioria por meios dos vídeos disponibilizados no YouTube.

Nos textos publicados em jornais de notícias ou revistas foram identificadas 65 revistas e 28 jornais e/ou informativos e boletins comerciais que publicam matérias específicas da área de agrárias, dos projetos dos INCT.

No acesso das revistas e jornais na web, 30 delas cobram pelo acesso, seja impresso ou online, e 51 possuem link para as matérias. Esses canais informais são importantes fontes por fornecerem informação atualizada e em linguagem acessível ao público leigo. Todos os institutos se comunicam por este canal, sendo os mais expressivos, o INCT Ciência Animal e INCT Citros, o que reforça o papel de difusão da informação exercido pelos INCT, no qual a divulgação da ciência deve direcionar-se ao grande público em geral, com a finalidade de democratizar o acesso ao conhecimento científico, por meio de mensagens elaboradas e enviadas pelos diversos canais de informação acessíveis ao público leigo (BUENO, 2010; MASSARANI, 1998; VARELLA et al., 2012).

$\mathrm{Na}$ análise das Redes sociais, websites e blogs, se destaca o INCT Fixação Biológica de Nitrogênio, com quatro itens, dos quais três estão disponíveis na web.

A Tabela 6 apresenta o total da publicação técnica em relação ao tipo de acesso.

Tabela 6 - Publicação técnica dos INCT de Agrárias por tipo de acesso (2013 a 2015)

\begin{tabular}{lccccc}
\hline Instituto & Não localizado & Disponível na web & Compra & Total & Total \% \\
\hline $\begin{array}{l}\text { Apresentações de trabalho - conferências } \\
\text { e palestras }\end{array}$ & $745(96,0 \%)$ & $31(4,0 \%)$ & $-(0,0 \%)$ & $\mathbf{7 7 6}$ & $\mathbf{5 1 , 6 \%}$ \\
$\begin{array}{l}\text { Entrevistas, mesas redondas, programas e } \\
\text { comentários na mídia }\end{array}$ & $112(51,1 \%)$ & $107(48,9 \%)$ & $-(0,0 \%)$ & $\mathbf{2 1 9}$ & $\mathbf{1 4 , 6 \%}$ \\
$\begin{array}{l}\text { Trabalhos e produções técnicas } \\
\text { Curso de curta duração ministrado }\end{array}$ & $99(45,8 \%)$ & $115(53,2 \%)$ & $2(0,9 \%)$ & $\mathbf{2 1 6}$ & $\mathbf{1 4 , 4 \%}$ \\
$\begin{array}{l}\text { especialização ou extensão } \\
\text { Textos em jornais de notícias ou revistas }\end{array}$ & $18(19(98,9 \%)$ & $2(1,1 \%)$ & $-(0,0 \%)$ & $\mathbf{1 8 2}$ & $\mathbf{1 2 , 1 \%}$ \\
Redes sociais, websites e blogs & $2(16,7 \%)$ & $51(51,0 \%)$ & $30(30,0 \%)$ & $\mathbf{1 0 0}$ & $\mathbf{6 , 6 \%}$ \\
Total & $\mathbf{1 . 1 5 7}$ & $10(83,3 \%)$ & $-(0,0 \%)$ & $\mathbf{1 2}$ & $\mathbf{0 , 8} \%$ \\
Total \% & $\mathbf{7 6 , 9 \%}$ & $\mathbf{3 1 6}$ & $\mathbf{3 2}$ & $\mathbf{1 . 5 0 5}$ & $\mathbf{1 0 0 \%}$ \\
\hline
\end{tabular}

Fonte: Elaborado pela Autora (2016).

A maior parte da publicação técnica 1.157 (76,9\%) não foi recuperada na web, sendo que $316(21,0 \%)$ dela foi localizada.

As Entrevistas, mesas redondas, programas e comentários na mídia e os Textos em jornais de notícias ou revistas apresentaram um total de $158(50,0 \%)$ de itens disponíveis na web. Foi um resultado expressivo, tendo em vista que estas fontes de informação são de fácil acesso pela sociedade e se traduzem em comunicação escrita e oral de fácil entendimento, pelo fato de serem entrevistas em veículos de comunicação como televisão e rádio, mais fácil ao público leigo.

\subsection{Acesso às publicações tecnológicas}

Em relação à publicação tecnológica, as Patentes e registros foram pesquisados em bases de dados especializadas como: WTO - World Trade Organization; WIPO - World Intellectual Property Organization; USPTO; Ministério da Agricultura, Serviço Nacional de Proteção de Cultivares (SNPC) e no INPI. O resultado foi 
de $48 \%$ dos documentos recuperados. Optou-se por buscar as Patentes e Registros em bases de dados especializadas, pois no Google não foi obtido acesso a este tipo de documento.

Em relação aos Produtos tecnológicos não foi encontrada publicação disponível para ser acessada, sendo recuperado apenas um item de informação (8\%), o qual se tratava de um descritivo detalhado sobre o produto patenteado.

Na categoria Programa de computador foi recuperado apenas um documento, que se referia ao manual do software elaborado.

A Tabela 7 apresenta o total da publicação tecnológica em relação ao tipo de acesso. Percebe-se que dos 113 itens avaliados, 45 (39,8\%) estavam disponíveis na web e 68 (60,2\%) não foram localizados.

Tabela 7 - Publicação tecnológica dos INCT de Agrárias por tipo de acesso (2013 a 2015)

\begin{tabular}{lcccc}
\hline Instituto & Não localizado & Disponível na web & Total & Total \% \\
\hline Patentes e registros & $47(52,2 \%)$ & $43(47,8 \%)$ & 90 & $\mathbf{7 9 , 6 \%}$ \\
Produtos tecnológicos & $14(93,3 \%)$ & $1(6,7 \%)$ & $\mathbf{1 5}$ & $\mathbf{1 3 , 3 \%}$ \\
Programa de computador & $7(87,5 \%)$ & $1(12,5 \%)$ & $\mathbf{8}$ & $\mathbf{7 , 1} \%$ \\
Total & 68 & 45 & $\mathbf{1 1 3}$ & $\mathbf{1 0 0 \%}$ \\
Total \% & $\mathbf{6 0 , 2 \%}$ & $\mathbf{3 9 , 8 \%}$ & $\mathbf{1 0 0 \%}$ & \\
\hline
\end{tabular}

Fonte: Dados da pesquisa (2016).

A Tabela 8 apresenta o total da publicação científica, técnica e tecnológica, no que se ressalta que 1.868 $(55,5 \%)$ dos itens não foram localizados; 1.186 (35,2\%) estavam disponíveis na web e 311 (9,2\%) são obtidos por meio de pagamento.

Tabela 8 - Publicação Científica, Técnica e Tecnológica dos INCT de Agrárias por tipo de acesso (2013 a 2015)

\begin{tabular}{lccccc}
\hline Tipo de publicação & Não localizado & Disponível na web & Compra & Total & Total \% \\
\hline Científica & $643(36,8 \%)$ & $825(47,2 \%)$ & $279(16,0 \%)$ & $\mathbf{1 . 7 4 7}$ & $\mathbf{5 1 , 9 \%}$ \\
Técnica & $1.157(76,9 \%)$ & $316(21,0 \%)$ & $32(2,1 \%)$ & $\mathbf{1 . 5 0 5}$ & $\mathbf{4 4 , 7 \%}$ \\
Tecnológica & $68(60,2 \%)$ & $45(39,8 \%)$ & $-(0,0 \%)$ & $\mathbf{1 1 3}$ & $\mathbf{3 , 4} \%$ \\
Total & $\mathbf{1 . 8 6 8}$ & $\mathbf{1 . 1 8 6}$ & $\mathbf{3 1 1}$ & $\mathbf{3 . 3 6 5}$ & $\mathbf{1 0 0 \%}$ \\
Total \% & $\mathbf{5 5 , 5 \%}$ & $\mathbf{3 5 , 2} \%$ & $\mathbf{9 , 2} \%$ & $\mathbf{1 0 0 \%}$ & \\
\hline
\end{tabular}

Fonte: Dados da pesquisa (2016).

A publicação científica possui $825(47,2 \%)$ de documentos disponíveis na web, isso devido ao fato de a informação estar estruturada e manter um padrão, permitindo a recuperação eficaz de documentos. A publicação técnica obteve o percentual de 316 (21,0\%) de documentos recuperados, enquanto a tecnológica apresentou $45(39,8 \%)$ de itens localizados na web.

A publicação científica possui 279 (16,0\%) materiais disponíveis para aquisição por meio de compra, por ter em seu escopo artigos, livros, capítulos e anais de eventos acessíveis por meio de pagamento, enquanto a publicação técnica apresentou $32(2,1 \%)$ documentos publicados em jornais e revistas técnicas acessíveis por meio de pagamento. 
A publicação técnica apresenta 1.157 (76,9\%) dos itens não localizados na web, a publicação tecnológica apresentou $68(60,2 \%)$ e a publicação científica apresentou $643(36,8 \%)$ de documentos não localizados na web.

\section{Considerações finais}

A comunicação científica é importante para a construção do conhecimento científico. Resultados de pesquisa que não são divulgados significam um esforço desperdiçado (MEADOWS, 1999). Isto está previsto no modelo tradicional de comunicação científica, idealizado por Garvey e Griffith (1972), no qual a pesquisa passa por um processo desde seu início, que envolve a criação, compartilhamento e uso do conhecimento científico pela sociedade, pesquisadores e seus pares.

Este artigo apresentou um panorama da publicação científica, técnica e tecnológica dos pesquisadores dos Institutos Nacionais de Ciência e Tecnologia da área de Agrárias, sendo então investigados os 12 Institutos da área entre os anos de 2013 e 2015, por meio do currículo dos pesquisadores, disponíveis na Plataforma Lattes do CNPq, cuja análise se dividiu nos objetivos específicos deste trabalho.

O número total de pesquisadores, somando os 12 Institutos foi de 444 pesquisadores, após as exclusões realizadas. O vínculo institucional predominante é em Universidades Federais (72\%) e na Embrapa (12\%), que representam $84 \%$ dos vínculos institucionais dos pesquisadores. Do total de pesquisadores, 201 são bolsistas de produtividade do CNPq, representando $45,3 \%$ do total. A maioria dos pesquisadores se concentra em cinco áreas principais: Agronomia, Zootecnia, Medicina Veterinária, Microbiologia e Parasitologia e, Biofísica e Bioquímica.

As publicações científicas apresentaram um total de 10.972 registros, as publicações técnicas, um total de 2.196 registros e a publicação tecnológica apresentou o total de 153 registros, nos três anos de análise.

Das categorias da publicação científica, 52,0\% foram artigos publicados em periódicos científicos, o que reforça a função principal do periódico que é a de divulgar os resultados de pesquisa para a comunidade científica, garantindo o registro e acesso, bem como seguindo os padrões de qualidade da ciência, inserido dentro do sistema de comunicação científica.

Na publicação técnica, as Apresentações de trabalho, conferências e palestras e as e Produções técnicas apresentam o total de $63,3 \%$ dos tipos de publicação técnica. Este resultado ressalta que a comunicação informal, mesmo sendo efêmera, ainda aparece bastante na publicação dos Institutos como uma forma de difusão das pesquisas realizadas, que aparecem no processo de comunicação científica, mesmo antes da publicação dos artigos, antes ainda da conclusão da pesquisa. A apresentação de trabalhos em eventos é uma forma de os pesquisadores comunicarem a ciência aos pares e submeter as suas pesquisas à avaliação antes de ser publicada formalmente.

Na publicação tecnológica, o destaque para a quantidade de itens levantados foi em relação às patentes e registros, que apresentaram 110 itens do total de 153 registros.

Na pesquisa de acesso aos documentos os artigos de periódicos e anais de eventos são mais comuns de serem encontrados, assim como os livros. Destaca-se que $78 \%$ das revistas cobram pelo acesso aos artigos e, $49 \%$ dos livros precisam ser comprados para serem lidos. A vantagem desses documentos, por serem formais, é a de que ficam armazenados por longo período de tempo em bases de dados eletrônicas e bibliotecas, sejam físicas ou virtuais, e, por isso, são considerados arquétipos de comunicações formais, como afirma Meadows (1999).

Pode-se perceber que a maior parte da publicação técnica não foi recuperada na web, com 76,9\%, sendo que $21,0 \%$ das publicações foram localizadas, que se referem aos canais informais de comunicação científica, que, conforme explica Le Coadic (1996) são aqueles nos quais a informação armazenada não é comprovada e é de difícil recuperação. Esse número se deve à falta de informação no cadastramento dos itens de informação no currículo Lattes, que dificultou a recuperação da informação/documento ou ainda pela não disponibilidade do documento na web. 
A publicação científica possui maior número de materiais disponíveis para aquisição por meio de compra (16,0\%), por ter em seu escopo os artigos, livros, capítulos e alguns anais de eventos que só são acessíveis por meio de pagamento. A publicação técnica apresentou 2,1\%, categoria na qual estão os textos publicados em jornais e revistas, que são, em sua maioria, acessíveis por meio de pagamento.

No total da publicação científica, técnica e tecnológica ressalta-se que 55,2\% dos itens cadastrados no currículo Lattes dos pesquisadores não foram localizados; 35,2\% estavam disponíveis na web e 9,2\% são obtidos por meio de pagamento.

Os INCT da área de Agrárias possuem uma produção científica, técnica e tecnológica expressiva, apresentando o total de 13.321 publicações em três anos de análise, das quais 42,9\% são artigos publicados em periódicos científicos nacionais e internacionais. Para Mugnaini (2013), "o salto quantitativo de artigos científicos no Brasil acontece devido aos esforços que resultaram na infraestrutura institucional da pós-graduação nas últimas décadas", como é o caso dos Institutos do Programa do CNPq que são compostos por uma entidade sede e por uma rede de grupos pesquisa organizada regional ou nacionalmente, no caso, as Universidades Federais (CONSELHO NACIONAL DE DESENVOLVIMENTO CIENTÍFICO E TECNOLÓGICO, 2008).

Outro fator que explica o aumento no número de publicações é o maior número de periódicos brasileiros, que publica predominantemente artigos do Brasil nas bases internacionais (MUGNAINI, 2013). Neste caso, vale destacar o número de revistas encontrado nesta pesquisa, que compreende o total de 1.008 títulos, pertencentes a 378 editoras científicas nacionais e internacionais diferentes. As Universidades brasileiras mantêm $10,42 \%$ das revistas analisadas.

As Universidades atuam como um dos principais stakeholders necessários para o desenvolvimento de revistas de acesso aberto de alta qualidade e são provedoras de recursos financeiros e humanos para a gestão e editoração de revistas científicas, além de fornecerem espaço físico em suas instalações e infraestrutura tecnológica. A quase totalidade dos editores no Brasil é formada por docentes e pesquisadores renomados e produtivos em suas áreas de atuação (NASSI-CALÒ, 2014). Esta informação vai ao encontro dos elementos apresentados pelos INCT, pois as equipes de pesquisa são formadas por doutores pesquisadores que publicam seus resultados de pesquisa por meio das publicações científicas, técnicas e tecnológicas aqui analisadas.

Ressalta-se que os INCT divulgam suas publicações científicas, técnicas e tecnológicas por meio dos canais formais e informais, dando-se destaque nas publicações disponibilizadas por meio de canais formais, que obteve o percentual de $83 \%$ do total produzido pelos INCT e $17 \%$ publicações por meio de canais informais.

Com o cenário apresentado conclui-se que os resultados das pesquisas chegam parcialmente aos pesquisadores, que assinam os títulos de periódicos por intermédio das universidades as quais estão vinculados. Por outro lado, diversos profissionais não vinculados a estas universidades, em busca da necessária e permanente atualização, enfrentam certa dificuldade em acessar as publicações, tendo em vista que o acesso acontece por meio de pagamento.

Segundo a UNESCO (2015), o Brasil é um dos maiores produtores de documentos científicos na área de agrárias, e parte significativa dos resultados obtidos com verbas públicas estão publicados em periódicos de editoras comerciais que exigem pagamento dos autores e ou de subscrição. É um caso no qual fica evidente a competência de um país que publica em revistas comerciais, alimentando o ciclo de privatização de trabalhos científicos criticado na literatura. 


\section{Referências}

ABADAL, E. Acceso abierto a la ciencia. Barcelona: Editorial UOC, 2012. (Colección El profesional de la información).

ALBAGLI, S. Ciência aberta em questão. In: ALBAGLI, Sarita; MACIEL, Maria Lucia; ABDO, Alexandre Hannud (Orgs.). Ciência aberta, questões abertas. Brasília: IBICT; Rio de Janeiro: UNIRIO, 2015, p. 9-25.

ALPERIN, J. P. Open Access indicators: assessing growth and use of open access resources from developing regions: the case of Latin America. In ALPERIN, J. P.; BABINI, D.; FISCHMAN, G. (Orgs.). Open Access Indicators and Scholarly Communications in Latin America. Buenos Aires: CLACSO; Buenos Aires: Unesco, 2014.

BATTAGLIA, M. da G. B. A inteligência competitiva modelando o sistema de informação de clientes Finep. Ciência da Informação, Brasília, v. 28, n. 2, May/Aug. 1999. Disponível em: <http://dx.doi.org/10.1590/S0100-19651999000200012 >. Acesso em: 20 nov. 2015.

BUENO, W. da C. Jornalismo científico no Brasil: os compromissos de uma prática dependente. 1984. 364f. Tese (Doutorado em Comunicação) - Departamento de Jornalismo e Editoração, Escola de Comunicação e Artes, Universidade de São Paulo, São Paulo, 1984.

Jornalismo científico: revisitando o conceito. In: VICTOR, C.; CALDAS, G.; BORTOLIERO, S. (Orgs.). Jornalismo científico e desenvolvimento sustentável. São Paulo: All Print, 2009. p.157-78.

Comunicação científica e divulgação científica: aproximações e rupturas conceituais. Informação e Informação, Londrina, v. 15, n. esp. p. 1-12, 2010. Disponível em: <http://www.uel.br/revistas/uel/index.php/informacao/article/view/6585/6761>. Acesso em: 02 jan. 2016.

BUFREM, L. S. et al. Produção científica em Ciência da Informação: análise temática em artigos de revistas brasileiras. Perspectivas em Ciência da Informação, v. 12, n. 1, p. 38-49, jan./abr. 2007. Disponível em: $<$ http://www.scielo.br/pdf/pci/v12n1/03.pdf. >. Acesso em: 04 jan. 2016.

CHAN, L.; OKUNE, A.; SAMBULI, N. O que é ciência aberta e colaborativa, e que papéis ela poderia desempenhar no desenvolvimento? In: ALBAGLI, Sarita; MACIEL, Maria Lucia; ABDO, Alexandre Hannud (Orgs.). Ciência aberta, questões abertas. Brasília: IBICT; Rio de Janeiro: UNIRIO, 2015. p. 91-119.

CONSELHO NACIONAL DE DESENVOLVIMENTO CIENTÍFICO E TECNOLÓGICO. Chamada INCT: MCTI/CNPq/CAPES/FAPs, no 16/2014.CNPq, 2014. 38p. Disponível em: <http://www.cnpq.br/documents/10157/b91b7566-2110-4a29-9704-88cdd324e072.>. Acesso em: 16 out. 2015.

Programa institutos nacionais de C\&T: documento de orientação aprovado pelo comitê de coordenação, em 29 de julho de 2008. CNPq, 2008, 12p. Disponível em: <http://www.cnpq.br/editais/ct/2008/docs/015 anexo.pdf>. Acesso em: 18 nov. 2015

DELFANTI, A.; PITRELLI, N. Ciência aberta: revolução ou continuidade? Ciência aberta em questão. In: ALBAGLI, Sarita; MACIEL, Maria Lucia; ABDO, Alexandre Hannud (Orgs.). Ciência aberta, questões abertas. Brasília: IBICT; Rio de Janeiro: UNIRIO, 2015, p. 59-69.

DINIZ, M. M. DE M.; OLIVEIRA, M. de. Produção técnica nas agências de fomento à pesquisa: estudo de caso. Informação \& Sociedade, João Pessoa, v. 25, n. 1, p. 123-135, jan./abr. 2015. Disponível em: <http://www.ies.ufpb.br/ojs/index.php/ies/article/download/123/13195>. Acesso em: 19 set. 2016.

GARVEY, W. D., GRIFFITH, B. G. Communication and information processing within scientific disciplines: empirical findings for psychology. Information Storage and Retrieval. v. 8, p. 123-136, 1972.

GONÇALVES, J. E. P. Brasil é o penúltimo em ranking de patentes. Portal CNI, 23 abr. 2014. Disponível em: $<$ http://anprotec.org.br/site/2014/04/brasil-ocupa-penultima-posicao-em-ranking-de-patentes/>

GONZALEZ-DIAZ, C.; IGLESIAS-GARCIA, M.; CODINA, L. Presence of Spanish universities on scientific digital social networks: case of communication studies. Profesional de La Informacion, v. 24, n. 5, p. 640-647, sep./oct. 2015

INSTITUTO NACIONAL DA PROPRIEDADE INDUSTRIAL (INPI). Acesso à informação. 2016. Disponível em: $<$ http://www.inpi.gov.br/>. Acesso em: 20 dez. 2015.

LARIVIÈRE, V.; HAUSTEIN, S.; MONGEON, P. The oligopoly of academic publishers in the digital era. PLoS ONE, v. 10, n. 6 , e0127502, 2015. Disponível em: <https://doi.org/10.1371/journal.pone.0127502>. Acesso em: 05 dez. 2016.

LE COADIC, Y.-F. A ciência da informação. Brasília, DF: Briquet de Lemos, 1996.

LEITE, F. C. L. Acesso aberto à informação científica em agricultura: a experiência da Empresa Brasileira de Pesquisa Agropecuária (Embrapa). Liinc em Revista, v. 8, n. 2, 2012. Disponível em: <http://revista.ibict.br/liinc/index.php/liinc/article/view/503>. Acesso em: 13 nov. 2015. 
MACHADO, J. Dados abertos e ciência aberta. In: ALBAGLI, Sarita; MACIEL, Maria Lucia; ABDO, Alexandre Hannud (Orgs.). Ciência aberta, questões abertas. Brasília: IBICT; Rio de Janeiro: UNIRIO, 2015, p. 201-227.

MEADOWS, A. J. A comunicação científica. Brasília, DF: Brinquet de Lemos, 1999

MUELLER, S. P. M. O periódico científico. In: CAMPELLO, B. S.; CENDÓN, B. V.; KREMER, J. M. (Orgs.). Fontes de informação para pesquisadores e profissionais. Belo Horizonte: Ed. UFMG, 2000. p. 73-95.

MUGNAINI, R. Ciência: Análise: Internacionalização é desafio para melhorar qualidade da ciência nacional. Folha de São Paulo Online, abr. 2013. Disponível em: <http://www1.folha.uol.com.br/ciencia/2013/04/1266526-analiseinternacionalizacao-e-desafio-para-melhorar-qualidade-da-ciencia-nacional.shtml>. Acesso em: 10 abr. 2016.

NASSI-CALÒ, L. Estudo destaca os modelos de publicação em periódicos científicos do Brasil e Espanha. Scielo em Perspectiva, apr. 2014. Disponível em: <http://blog.scielo.org/blog/2014/04/25/estudo-destaca-os-modelos-depublicacao-em-periodicos-cientificos-do-brasil-e-espanha/\#.V5 LFdSUOrg>. Acesso em: 29 jul. 2016.

PEDROSA, R. H. de L.; CHAIMOVICH, H. Brasil. In: UNESCO. Relatório de Ciência da UNESCO: rumo a 2030: visão geral e cenário brasileiro. BRASIL: UNESCO. 2015, p. 39-57. Disponível em:

$<$ http://unesdoc.unesco.org/images/0023/002354/235407por.pdf>. Acesso em: 02 jan. 2016.

PINHEIRO, L. V. R. Fontes ou recursos de informação: categorias e evolução conceitual. Pesquisa Brasileira em Ciência da Informação e Biblioteconomia, Rio de Janeiro: IBICT, v. 1, n. 1, 50, 2006. Disponível em; <http://periodicos.ufpb.br/ojs/index.php/pbcib/article/view/8809>. Acesso em: 20 out. 2015.

PINHEIRO, L. V. R.; VALÉRIO, P. M.; SILVA, M. R. Marcos históricos e políticos da divulgação científica no Brasil. In: BRAGA, G. M.; PINHEIRO, L. V. R. (Org.). Desafios do impresso ao digital: questões contemporâneas de informação e conhecimento. Brasília: IBICT; UNESCO, 2009. p. 257-288

SANCHES MORA, A. M. A divulgação científica como literatura. Rio de Janeiro: Casa da Ciência/UFRJ, 2003

SILVA, R. C. da; HAYASHI, M. C. P. I. Revista Educação Especial: um estudo bibliométrico da produção científica no campo da Educação Especial. Revista Educação Especial, n. 31, p. 117-136, 2008. Disponível em: <http://cascavel.ufsm.br/revistas/ojs-2.2.2/index.php/educacaoespecial/article/viewFile/15/27>. Acesso em: 04 jan. 2016 .

STUMPF, I. R. C. A comunicação da ciência na universidade: o caso da UFRGS. In: MUELLER, S. P. M.; PASSOS, E.J. L. (Org.). Comunicação científica. Brasília: Universidade de Brasília, 2000. p. 107-121.

RODRIGUES, R. S; ABADAL, E. Scientific journals in Brazil and Spain: alternative publisher models. Journal of the American Society for Information Science and Technology, v. 65, n.10, p. 2145-2151, 2014.

TARGINO, M. das G. Comunicação científica: uma revisão de seus elementos básicos. Informação e Sociedade, João Pessoa, v. 10, n. 2, 2000. Disponível em: <http://www.ies.ufpb.br/ojs2/index.php/ies/article/view/326/248>. Acesso em: 02 jan. 2016.

Divulgação de resultados como expressão da função social do pesquisador. Intercom, Revista Brasileira de Ciências da Comunicação, v. 24, n. 1, 2001. Disponível em: <http://www.portcom.intercom.org.br/revistas/index.php/revistaintercom/article/viewArticle/1014>. Acesso em: 18 jul. 2015.

UNESCO. Relatório de Ciência da UNESCO: rumo a 2030: visão geral e cenário brasileiro. BRASIL: UNESCO. 2015. Disponível em: <http://unesdoc.unesco.org/images/0023/002354/235407por.pdf>. Acesso em: 02 jan. 2016.

VARELLA, U. do N. et al. Divulgação científica e mídia digital: Estudo comparativo entre a Fapeam e Fapesp. In: INTERCOM, SOCIEDADE BRASILEIRA DE ESTUDOS INTERDISCIPLINARES DA COMUNICAÇÃO XXXV CONGRESSO BRASILEIRO DE CIEENCIAS DA COMUNICACÃO, Anais... Fortaleza, CE - 3 a 7/9/2012. Disponível em: <http://www.academia.edu/5301409/Divulga\%C3\%A7\%C3\%A3o cient\%C3\%ADfica e m\%C3\%ADdia digital E studo comparativo entre a Fapeam e Fapesp Artigo Intercom >. Acesso em: 20 abr. 2015. 


\section{Dados dos autores}

Heloisa Costa

Mestra em Ciência da Informação pela Universidade Federal de Santa Catarina. Professora substituta no Departamento de Ciência da Informação, da Universidade Federal de Santa Catarina.

helocosta7@hotmail.com

\section{Márcio Matias}

Professor Adjunto do Departamento de Ciência da Informação da Universidade Federal de Santa Catarina (CIN/UFSC).

matias97@gmail.com

\section{Rosângela Schwarz Rodrigues}

Professora Associada do Departamento de Ciência da Informação da Universidade Federal de Santa Catarina (CIN/UFSC).

rosangela.rodriguesufsc@gmail.com

Recebido - Received: 2016-12-21

Aceitado - Accepted: 2017-12-28

\section{$(\mathrm{cc}) \mathrm{EY}$}

This work is licensed under a Creative Commons Attribution 4.0

United States License.

\section{ULIS D-Sente}

This journal is published by the University Library System of the University of Pittsburgh as part of its D-Scribe Digital Publishing Program and is cosponsored by the University of Pittsburgh Press. 